\title{
LVII. On the determination of the critical volume
}

\section{Sydney Young D.Sc.}

To cite this article: Sydney Young D.Sc. (1892) LVII. On the determination of the critical volume, Philosophical Magazine Series 5, 34:211, 503-507, DOI: 10.1080/14786449208620365

To link to this article: http://dx.doi.org/10.1080/14786449208620365

$$
\text { 曲 Published online: } 08 \text { May } 2009 .
$$

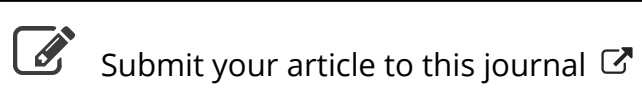

\footnotetext{
Џll Article views: 3
}

Q View related articles $\square$

Citing articles: 1 View citing articles 5 


\section{$\left[\begin{array}{ll}503 & ]\end{array}\right.$}

LVII. On the Determination of the Critical Toleme. By Sydney Young, D.Se., University Colleye, Bristel*.

A BOUT a year ago I read a paper before the Plysical A Society (Phil. Mag. Feb. 1892, p. 153) on the "Genteralizations of Van der Waals regarding Corresponding Temperatures, Pressures, and Volumes ;" and at the close of the paper, after calling attention to the extreme difficulty attending the determination of the critical volume, I described a method by which the relative critical volumes of various substances could be ascertained. At that time it appeared to me that the direct determinations of the critical volumes of benzene, fluorbenzene, chlorobenzene, and acetic acid were probably approximately correct; and I was supported in this view by the fact that the ratios of the observed volumes to that of fluorbenzene were practically identical with the ratios obtained by the graphical method then described.

I therefore assumed that the observed critical molecular volume of fluorbenzene was correct, and calculated the volumes of the other substances from their ratios to that of fluorbenzene, and gave these values as the probable? critical molecular volumes of the other eleven substances. It was observed, however, that the critical volumes of the three alcohols and of ether obtained by this method were considerably lower than those previously deduced by Dr. Ramsay and myself, and were also lower than those calculated by M. Guye (Compt. Rend. cxii. p. 1257). Finally, I pointed out that if these values are taken as correct it would appear that the ratio of the actual critical density to the theoretical (for a "perfect" gas) is for many substances about $4 \cdot 4$.

Since then, M. E. Mathias has shown (Compt. Rend. cxr. p. 35) that the critical densities of the substances referred to in my paper may be determined by the method described by M.M. Cailletet and Mathias (Compt. Rend. cii. p. 1202, civ. p. 1563). The method has also been found by M. Amagat to give excellent results with carbon dioxide, and by Mr. G. L. Thomas and myself with five of the lower esters; and I have therefore much pleasure in acknowledging the correctness both of the method (except, perhaps, in the case of the alcohols) and of the critical densities calculated by M. Mathias, and I have no hesitation in accepting these values in place of those previously adopted.

I have myself made an independent calculation of the critical densities of the twelve substances by this method, and the results $I$ have obtained are practically identical

* Communicated by the Physical Society: read October 28, 1892. 
(except in the case of the alcohols) with those given by M. Mathias.

The law of MM. Cailletet and Mathias may be described very briefly as follows:- The means of the densities of any substance in the state of liquid and of saturated vapour, when mapped against the temperature, fall on a straight line. I quite agree with $M$. Mathias that in the great majority of cases the verification of the law is perfect; but with the three alcohols, especially methyl alcohol, there appears to me to be very decided curvature, too pronounced to be neglected, and I think it must be admitted that these substances behave exceptionally in this as in many other respects.

M. Mathias admits that at low temperatures the alcohols cease to follow the law ; but he is satisfied with the agreement betw'een the observed and calculated mean densities for a range of $200^{\circ}$ from the critical point. The constants employed by M. Mathias for etbyl alcohol can be ascertained from his paper, and I give below the mean densities calculated from these constants, together with those calculated from the observed molecular volumes given in my paper (loc. cit.).

The constants for the formula $\mathrm{D}=\mathrm{A}+$ at are :$A=\cdot 4149, \quad \alpha=-0005576, \quad t=$ temperature (Centigrade).

Means of Densities of Liquid and Saturated Vapour.

\begin{tabular}{|c|c|c|c|}
\hline $\begin{array}{l}\text { 'Temperature, } \\
\text { Centigrade. }\end{array}$ & Observed. & Calculated. & $\Delta \times 1000$ \\
\hline $\begin{array}{c}22 \cdot 4 \\
39 \cdot 45 \\
65 \cdot 75 \\
89 \cdot 7 \\
105 \cdot 55 \\
128 \cdot 1 \\
144 \cdot 65 \\
151 \cdot 65 \\
163 \cdot 8 \\
187 \cdot 9 \\
206 \cdot 35 \\
221 \cdot 35 \\
229 \cdot 2 \\
234 \cdot 3 \\
238 \cdot 9 \\
243 \cdot 1\end{array}$ & $\begin{array}{l}\cdot 3937 \\
\cdot 3865 \\
\cdot 3749 \\
\cdot 3636 \\
\cdot 3560 \\
\cdot 3442 \\
\cdot 3350 \\
\cdot 3309 \\
\cdot 3240 \\
\cdot 3104 \\
\cdot 2998 \\
\cdot 2899 \\
\cdot 2850 \\
\cdot 2811 \\
\cdot 2781 \\
\cdot \ldots . .\end{array}$ & $\begin{array}{l}\cdot 4024 \\
\cdot 3929 \\
\cdot 3782 \\
\cdot 3649 \\
\cdot 3560 \\
\cdot 3435 \\
\cdot 3342 \\
\cdot 3303 \\
\cdot 3236 \\
\cdot 3101 \\
\cdot 2998 \\
\cdot 2915 \\
\cdot 2871 \\
\cdot 2843 \\
\cdot 2817 \\
\cdot 2793\end{array}$ & $\begin{array}{r}+87 \\
+64 \\
+33 \\
+16 \\
0 \\
-7 \\
-8 \\
-6 \\
=4 \\
-3 \\
0 \\
+16 \\
+21 \\
+32 \\
+36\end{array}$ \\
\hline
\end{tabular}

From the above differences it will, I think, be concluded that there is considerable curvature of the "diameter" in the case of ethyl alcohol, and with methyl alcohol it would be still more marked.

I now give a revised table of the critical densities and 
of the Critical Volume.

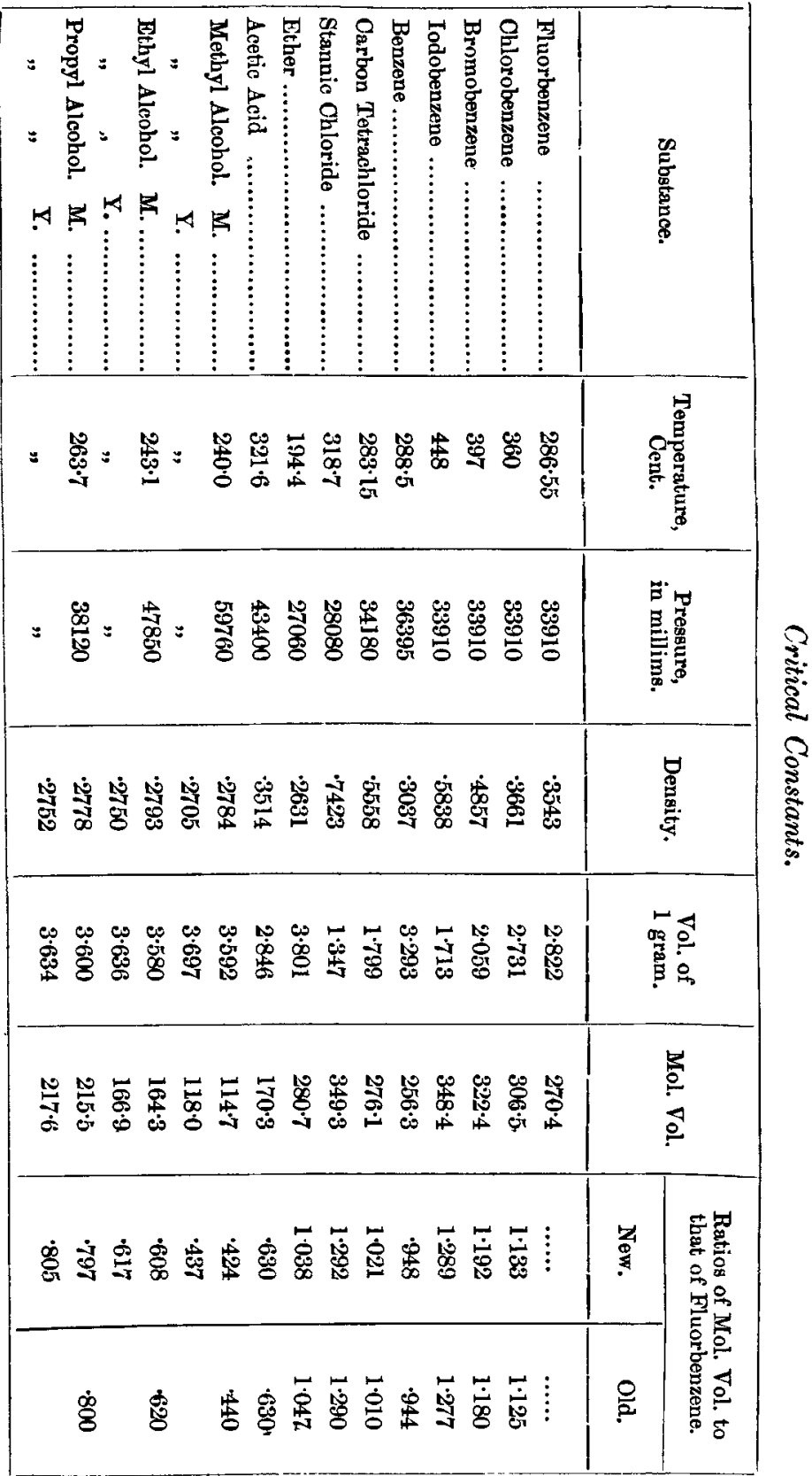


volumes of the twelve substances, adding, for the sake of convenience, the critical temperatures and pressures. The eritical densities are those calculated by M. Mathias; but in the case of the alcohols I give also the values which I have obtained by the same method, taking into account the curvature of the "diameter." The critical volumes of a gram and molecular volumes are calculated from the densities. The last two columns contain the ratios of the new critical molecular volumes to that of fluorbenzene, together with the ratios given on p. 184 of my previons paper and obtained by the graphical method there described. It will be seen that these ratios show satisfactory agreement.

As regards the alcobols it will be noticed that, if the curvature of the diameter is taken into account, the critical densities are lower and the volumes higher ; also that the ratios of the critical molecular volumes to that of fluorbenzene agree better with those obtained by the graphical method.

It may be pointed out that if the generalizations of Van der Waals were strictly true, the angular coefficients $(\alpha)$ of the diameters of different substances should be directly proportional to their critical densities and inversely proportional to their absolute critical temperatures, or that for any substance

$$
\alpha=\text { const. } \times \frac{\mathrm{D}}{\mathrm{T}} ; \text { or } \frac{\alpha \mathrm{T}}{\mathrm{D}}=\text { const. }
$$

I have calculated the values of this "constant" for the substances mentioned in this paper (with the exception of methyl and propyl alcohol) and for the five esters studied by Mr. G. L. Thomas and myself.

\begin{tabular}{|c|c|c|c|c|c|}
\hline Substance. & $\frac{a^{T} \mathbf{T}}{\bar{D}}$ & Substance. & $\frac{a T}{D}$. & Substance. & $\begin{array}{c}\alpha \mathbf{T} \\
\overline{\mathbf{D}}\end{array}$ \\
\hline Fluorbenzene & .932 & Carbon Tetrachloride & 899 & Methyl Formate... & .997 \\
\hline Chlorobenzene & .953 & Stannic Chloride .. & 988 & cetate ... & 1.047 \\
\hline Bromobenzene & .957 & Ether ................... & .972 & Ethyl Formate ... & 1061 \\
\hline Iodobenzene & .957 & Acetic Acid............ & $\cdot 993$ & Ethyl Acetate ..... & $1 \cdot 055$ \\
\hline Benzene ...... & .921 & Ethyl Alcohol * ...... & 1.030 & Methyl Propionate & $1 \cdot 021$ \\
\hline
\end{tabular}

It can hardly be said that there is more than a rough approximation to constancy in the values of $\frac{\alpha \mathrm{T}}{\mathrm{D}}$.

I have recalculated the ratios of the actual to the theoretical critical densities, and the results are given in the following table :-

* M. Mathias' value of $a$. 
$\begin{array}{lll}\text { Fluorbenzene } \ldots \ldots & 3 \cdot 79 \\ \text { Chlorobenzene } & \ldots & 3 \cdot 78 \\ \text { Bromobenzene } & \ldots & 3 \cdot 81 \\ \text { Iodobenzene } \ldots \ldots & 3 \cdot 79 \\ \text { Benzene ... . . . . . } & 3 \cdot 71 \\ \text { Carbon Tetrachloride. } & 3 \cdot 66\end{array}$

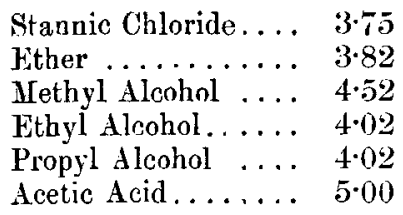

The first eight numbers agree fairly well; and it may bo stated that for many substances the ratio of the actual critical density to the theoretical density ( $f$ or a perfect gas) is about $3 \cdot 8$. The alcohols, notably methyl alcohol, and acetic acid, form exceptions to this law, and in the case of the esters the ratios $(3 \cdot 89$ to $3 \cdot 95)$ are rather high.

LVIII. On the Determination of the Critical Density. By Srdney Young, D.Sc., and G. L. Thomas, B.Se., University College, Bristol*.

T T has been shown by M. E. Mathias (Compt. Rend. cxv. 1 p. 35) that the method of determining the Critical Density proposed by MM. Cailletet and Mathias (Compt. Rend. cii. p. 1202, civ. p. 1563) gives good results in a considerable number of cases. We have recently investigated some of the thermal properties of five of the lower esters, and find that these substances afford further proof of the truth of the "Law of the Diameter" described by these authors. We therefore think it may be well to give the data illustrating this law, without waiting for the completion of the work on the remaining esters.

The law of the diameter may be briefly explained as follows:-It is well known that if the densities of any substance, both as liquid and as saturated vapour, be mapped as ordinates against the temperatures as abscissæ, they fall on a continuous curve which passes through the critical point. This curve possesses, according to MM. Cailletet and Mathias, the characteristic property that the locus of the middle points of chords parallel to the axis of ordinates is a straight line. If this is so, it follows that the ordinate of the point on the diameter corresponding to the critical temperature gives the critical density.

That the law holds very closely for the esters so far investigated is shown by the results tabulated below. The densities of each substance, both in the state of liquid and of saturated vapour, together with the means of these values,

* Communicated by the Physical Society: read October 28, 1892. 